\title{
Episiotomy practice and associated factors among mothers who gave birth at public health facilities in Metema district, northwest Ethiopia
}

Enyew Woretaw ${ }^{1}$, Muluken Teshome ${ }^{2}$ and Muluneh Alene $2^{2^{*}}$

\begin{abstract}
Background: Episiotomy is a surgical incision of the perineum to hasten the delivery. There is a scarce of information related to episiotomy practice, and its associated factors, in developing countries, including Ethiopia. Thus, this study was aimed to determine the level of episiotomy practice and to identify its determinants at public health facilities of Metema district, northwest, Ethiopia.

Methods: Institutional-based cross sectional study was conducted among 410 delivered mothers from March 1 to April 30, 2020. We recruited study participants using systematic random sampling technique. Data were entered to Epi data version 3.1 and exported to STATA version 14 for statistical analysis. Stepwise backward elimination was applied for variable selection and model fitness was checked using Hosmer and Lemshows statistics test. Adjusted odds ratio with the corresponding 95\% confidence interval was used to declare the significance of variables.
\end{abstract}

Results: In this study, the magnitude of episiotomy practice was found $44.15 \%$ (95\% Cl 39.32-48.97). Vaginal instrumental delivery (AOR 3.04, 95\% Cl 1.36-6.78), perineal tear (AOR 3.56, 95\% Cl 1.68-7.55), age between 25 and 35 (AOR $0.11,95 \% \mathrm{Cl} 0.05-0.25$ ), birth spacing less than 2 years (AOR $4.76,95 \% \mathrm{Cl} 2.31-9.83$ ) and use of oxytocin (AOR 2.73, $95 \% \mathrm{Cl} 1.19-6.25)$ were factors significantly associated with episiotomy practice.

Conclusions: Magnitude of episiotomy practice in this study is higher than the recommended value of World Health Organization (WHO). Instrumental delivery, age, oxytocin, birth spacing and perineal tear were significant factors for episiotomy practice. Thus, specific interventions should be designed to reduce the rate of episiotomy practice.

\section{Plain English summary}

The routine use of episiotomy practice is not recommended by WHO. A study that compares routine episiotomy with restrictive episiotomy suggests that the latter is associated with less posterior perineal trauma, less need for suturing, and fewer complications related to healing. In addition, though, the rate of episiotomy has been declined in developed countries, still it remains high in less industrialized countries.

The data for this study were taken at public health facilities of Metema district, northwest, Ethiopia. We included a total of 410 delivered mothers. The magnitude of episiotomy practice was found $44 \%$. This result was higher than the recommended value of WHO. The WHO recommends an episiotomy rate of 10\% for all normal deliveries.

*Correspondence: mulunehadis@gmail.com

2 Department of Public Health, Debre Markos University, Debre Markos, Ethiopia

Full list of author information is available at the end of the article permits use, sharing, adaptation, distribution and reproduction in any medium or format, as long as you give appropriate credit to the original author(s) and the source, provide a link to the Creative Commons licence, and indicate if changes were made. The images or other third party material in this article are included in the article's Creative Commons licence, unless indicated otherwise in a credit line to the material. If material is not included in the article's Creative Commons licence and your intended use is not permitted by statutory regulation or exceeds the permitted use, you will need to obtain permission directly from the copyright holder. To view a copy of this licence, visit http://creativecommons.org/licenses/by/4.0/. The Creative Commons Public Domain Dedication waiver (http://creativeco mmons.org/publicdomain/zero/1.0/) applies to the data made available in this article, unless otherwise stated in a credit line to the data. 
The result of this study showed that episiotomy practice is common among mothers whose age group are 18-24. In addition, mothers whose labor were assisted by instrumental vaginal delivery are more likely to have episiotomy as compared to those delivered by normal vaginal delivery. Laboring mothers who had used oxytocin were about three times more likely to be exposed for episiotomy than laboring mothers who did not use oxytocin drug. Moreover, episiotomy practice was nearly five times more likely among mothers who had birth spacing of 2 years and less as compared to mothers who had birth spacing of more than 2 years.

Keywords: Episiotomy, Factors, Metema, District

\section{Background}

Episiotomy is performed to enlarge the birth outlet in order to facilitate the delivery of the fetus [1]. It is the surgical enlargement of the posterior aspect of the vagina by an incision to the perineum during the last part of the second stage of labor [2]. Even though seven episiotomy types have been identified, only three (midline, mediolateral, and lateral) are routinely used [3]. Types of episiotomy techniques are classified on millimeter distance from the incision point to the posterior fourchette and by angle from the sagittal or parasagittal plane in degrees [4]. Women with midline episiotomy, deep perineal tears occurred in twofold higher compared to women who underwent a medio-lateral episiotomy [5]. The routine use of episiotomy practice is not recommended by World Health Organization (WHO) for women undergoing spontaneous vaginal birth [6]. A meta-analysis of randomized controlled studies that compare routine episiotomy with restrictive episiotomy suggests that the latter is associated with less posterior perineal trauma, less need for suturing, and fewer complications associated with healing [2]. Though the rate of episiotomy has been declined in developed countries, still it remains high in less industrialized countries and East Asia [7].

Routine use of episiotomy originally began by Pomeroy in 1918 and this routine practice was accepted and taught in obstetrics services till 1970s, when the first consistent clinical trials questioning the value of episiotomy were published [8]. Since then many studies, reviews and metanalyses have evidenced that there is no scientific basis for maintaining the routine practice of episiotomy. The procedure is shown to increase intra and post-operative complications, suggesting its practice to be restricted to selected deliveries [9].

Its use has shown also poorer future sexual function, similar pelvic floor muscle strength, and similar urinary incontinence in comparison with women in whom episiotomy is used in a selective manner. Routine use of episiotomy has no evidence on any beneficial effect; on the contrary, there is clear evidence that it may cause harm such as a greater need for surgical repair and a poorer future sexual capability. In view of the available evidence the routine use of episiotomy should be abandoned and episiotomy rates $>30 \%$ are not justified. The $\mathrm{WHO}$ recommends an episiotomy rate of $10 \%$ for all normal deliveries. It is prescribed selectively for women who have past history of lower genital tract surgeries and for women who require assisted vaginal deliveries. For other women in labor, episiotomies may be given on emergency basis when there are presumed imminent perineal tear scar of lower genital track, operative vaginal delivery, macrosomia and tight perineum [10-13].

Strategies for changing practice those were challenging on current practice of episiotomy and on creating social and organizational environments that encourage motivation are more effective in reducing episiotomy rates [14]. A systematic review and meta-analysis that was done on episiotomy recommend that there is an urgent need to explore reasons for and devise programs to reduce the apparent higher rates of episiotomies in low and middle income countries (LMIC) at their medical facilities $[14,15]$. Complications of episiotomies include accidental extension into the anal sphincter or rectum, damage to the Bartholin's gland, unsatisfactory anatomic results such as skin tags, asymmetry or excessive narrowing of the introitus, vaginal prolapse, recto-vaginal fistula, fistula in ano, perineal pain that lasted an average of 5.5 days, oedema, increased blood loss, hematoma, infection and dehiscence [16-23].

Women who had given birth with episiotomy are at risk for psychological trauma, higher frequency of dyspareunia and insufficient lubrication than women who had given birth without episiotomy. Episiotomy may affect women's sex life during the second year postpartum with more frequent pain and vaginal dryness at intercourse, although the role of episiotomies in the causation of dyspareunia in the long term is not clear [24-26]. Study showed that mean time from delivery to maternal rest and time taken to bond with the infant were significantly longer in the episiotomy groups compared to mothers who delivered without episiotomy procedure. Perineal local infiltration of lidocaine during episiotomy procedure is risk for the newborn for toxication due to maternal perineal nerve block with lidocaine $[27,28]$.

Even though episiotomy practice is with a decreasing trend in some developed countries, but still statistics 
revealed that an overall high rates of episiotomy practice around the world. Episiotomy rates ranged from as low as $9.7 \%$ (Sweden) to $100 \%$ (Taiwan) that include both primiparous and multiparous women. Rates for only primiparas range from 63.3\% (South Africa) to 100\% (Guatemala), demonstrating that overall greater likelihood of primiparas will undergo episiotomies. In many parts of the world (e.g., Central and South America, South Africa, and Asia)in France population based study showed that episiotomy rate for vaginal deliveries overall significantly decreased from $26.7 \%$ in 2007 to $19.9 \%$ in 2014 [32, 33].

In our country study showed that, the prevalence of episiotomy at public health institutions of Akaki Kality in Addis Ababa, Axum town, shire town, at saint Paul's hospital Millennium medical college Addis Ababa and at Mizan Aman General Hospital the prevalence of episiotomy were found to be $35.2 \%, 41.44 \%, 35.4 \%, 65.4 \%, 30.6$ respectively [40-44]. Findings at a maternity school in Recife, Pernambuco, Brazil and in a tertiary care centre in Nigeria and in our country at Mizan Aman General Hospital and at Saint Paul's hospital Millennium Medical College identified that maternal age and place of residence were significant predictors of episiotomy practice [37, 38, 43-45]. Studies in France, Brazil, Iran, Nigeria, Republic of Congo, and in our country studies at Akaki Kality, Axum town, at Saint Paul's hospital Millennium Medical College and Mizan Aman general hospital identified that Primipara was significant factor for episiotomy practice [33, 37-39, 41, 43-51].

Findings in Israel, Kurdistan region, Republic of Congo, Zimbabwe and in our country at Mizan Aman general Hospital, at Akaki Kality and at Saint Paul's hospital Millennium Medical College showed that perineal laceration (tear), duration of second stage of labour more than $90 \mathrm{~min}$, ANC follow up history, time of delivery, previous history of episiotomy and known medical diseases were significant predictors for episiotomy practice [43, 44, 46, $47,49,52]$. Studies in Northeast of Iran, Brazil, Republic of Congo, Israel, Kurdistan region, Zimbabwe and in our country at Mizan Aman general Hospital, at Akaki Kality, at Saint Paul's hospital Millennium Medical College, at Axum town public health institution and at Jima teaching Hospital identified that birth weight of $4 \mathrm{~kg}$ and above, gestational age, presence of meconium, sex the neonate, breech and shoulder presentation and condition of fetal heart rate were significant factors for episiotomy practice [33, 37-39, 41, 43-55].

Studies in Zimbabwe, Brazil, Northeast of Iran, Republic of Congo, Israel, Kurdistan region, and in our country at Mizan Aman general Hospital, at Akaki Kality, at Saint Paul's hospital Millennium Medical College at Axum town, at Jima teaching Hospital and at Institutions of Shire Town showed that instrumental vaginal delivery especially, use of oxytocin, when doctors attending labor and use of analgesia were predictors of episiotomy practice [33, 37-39, 41-56].

Many countries have recognized that high episiotomy rates are an indicator of high rates of unnecessary obstetric interventions [57]. No question about the rationale for episiotomy, when there is a good indication for its performance. Obstetric perennial trauma is assumed to be a serious health problem for women as well as for their child during their childbirth. Since our country is struggling to improve maternal health, this kind of studies are must to be done in order to improve the well-being and quality of life of women as well [58].

Metema district is one of the hot spot area for HIV transmission in Ethiopia even in 2019 there were 20 mothers who were newly positive at labour and delivery room in this case interventions like episiotomy procedure may increase HIV transmission by $2 \%$ compared to normal delivery without episiotomy to the neonate $[30,59,60]$. So, after identifying the magnitude and associated factors of episiotomy practice at Metema District, it is important to give recommendations for this practice. Knowing the magnitude and associated factors of episiotomy with reasons of it in Metema district has a great role in guiding health professionals and health policy makers to identify factors for monitoring episiotomy practice. It also used to apply necessary preventive and appropriate measures to use evidence based restrictive episiotomy practice and to prepare uniform protocols and educational programs to guide episiotomy practice. Hence, the objective of this research was to assess proportions of episiotomy and associated factors among mothers who gave birth at public health facilities in Metema District, Northwest, Ethiopia, 2020.

\section{Methods}

\section{Study design, area and period}

An institutional based cross-sectional study was conducted in Metema District. Metema is one of a hottest District among five Districts in West Gondar Zone which is located $870 \mathrm{~km}$ Northwest from Addis Ababa, the capital of Ethiopia, and $315 \mathrm{~km}$ far from Bahirdar, a capital of Amhara National Regional State. The most popular crop is sesame. The health facilities in Metema district provided health services to more than 250,000 populations in 2019. Currently, about five health centers and one primary hospital were available in the catchment area of the District. There were more than 5740 deliveries among pregnant mothers in 2019 [61]. This study was conducted from March 1/2020 to April 30/ 2020. 


\section{Sample size and sampling procedures}

All women who gave birth vaginally at public health facilities in Metema District during data collection period were included in the study. Mothers who delivered twin and above since it is difficult which child was a factor for episiotomy were excluded.

The required sample size of the study participants for the first objective was determined by using single population proportion formula with basic assumption of $95 \%$ confidence interval, 5\% margin of error and $41.44 \%$ estimated proportion of vaginal delivery with episiotomy at public health institutions of Axum Town, Tigray region, from previous study [41] with $10 \%$ of non-response rate was taken to calculate the sample size.

In Metema district, there were one primary hospital and five health centers. All the six public health facilities were selected in Metema District and allocated the sample proportionally to all public health facilities based on their previous two months delivery reports. According to pre-assessment done, the two months average total vaginal delivery reports before the start of the study at public health facilities in Metema District were 840. Systematic random sampling technique was used to select the study participants then calculated $\mathrm{K}$ for each public health facilities which gave us 2 . Then the random number was selected from the numbers $[1,2]$, using lottery method in this way at Metema primary Hospital, Kokit health center and Mesha health center the selected number was 2 and for others 1 was selected by lottery method and this number was the first study participant to be included in the sample after that every other woman was included in the sample until the total sample size 410 for this study was obtained (Fig. 1).

\section{Variables}

The outcome variable was episiotomy done. The explanatory variables include Socio-demographic and economic factors, clinical and individual maternal factors, clinical and individual child factor and technical factors.

\section{Operational and term definition Episiotomy done}

Is a surgical procedure includes both anterior (defibulation) and posterolateral incisions of the vulva and perineum which is done by health care providers to enlarge the vaginal orifice during delivery.

\section{Birth spacing}

Interpregnancy interval between live births after the first live birth. Example, short birth interval if the mother gives birth every 2 year or less than 2 years [62].

\section{Oxytocin}

Is prescribed as a drug for obstetric and gynecological reasons and can help in child birth and considering as a factor in this study if it is given before 3rd stage of labor.

\section{Analgesia}

A drug for pain management consider if it is given before 3rd stage of labour.

\section{Perineal laceration or tear}

Is a tear of varying degrees (first to fourth) involving the perineum of women during vaginal birth [63].

\section{Data collection tool and procedure}

The questionnaire was adapted from previously known sources [40, 41]. Income was measured using wealth index by adopting questionnaire from Ethiopian demographic health survey 2016 assuming the income level of participants of rural and urban households differently and it has 15 questions [64]. The questionnaire had five sections with five questions related to socio-demographic characteristics, twelve questions related to clinical and individual maternal factors, six questions related to clinical and individual child factors and seven questions related to technical factors. Data were collected through face to face interview using structured, pre-tested questionnaire and reviewing maternal records (for questions that couldn't answer by interviewer only) through trained data collectors. The questionnaire was translated from English language to local language Amharic. Seven BSc midwives were recruited to collect data and two BSc midwifes for supervision. The selection criteria of data collectors include interest to participate, being disciplined and punctuality at work. Data were collected in the immediate post-natal period, if conditions unfavorable, it was extended up to $24 \mathrm{~h}$ post-delivery.

\section{Data quality control}

One day training was given for 7BSc midwifes on data collection and 2BSc midwifes about supervision during data collection and interviewing approaches. Five percent Pre-test was done in Quara District health facilities before actual data collection was started, and necessary corrections were made accordingly. Data collection completeness and consistency was reviewed and checked by the supervisors and principal investigator at the end of each data collection day. The principal investigator was also closely supervising the activity on daily basis.

\section{Data processing and analysis}

After coding and checking for completeness and consistency, data were entered in to computer using Epi-data 


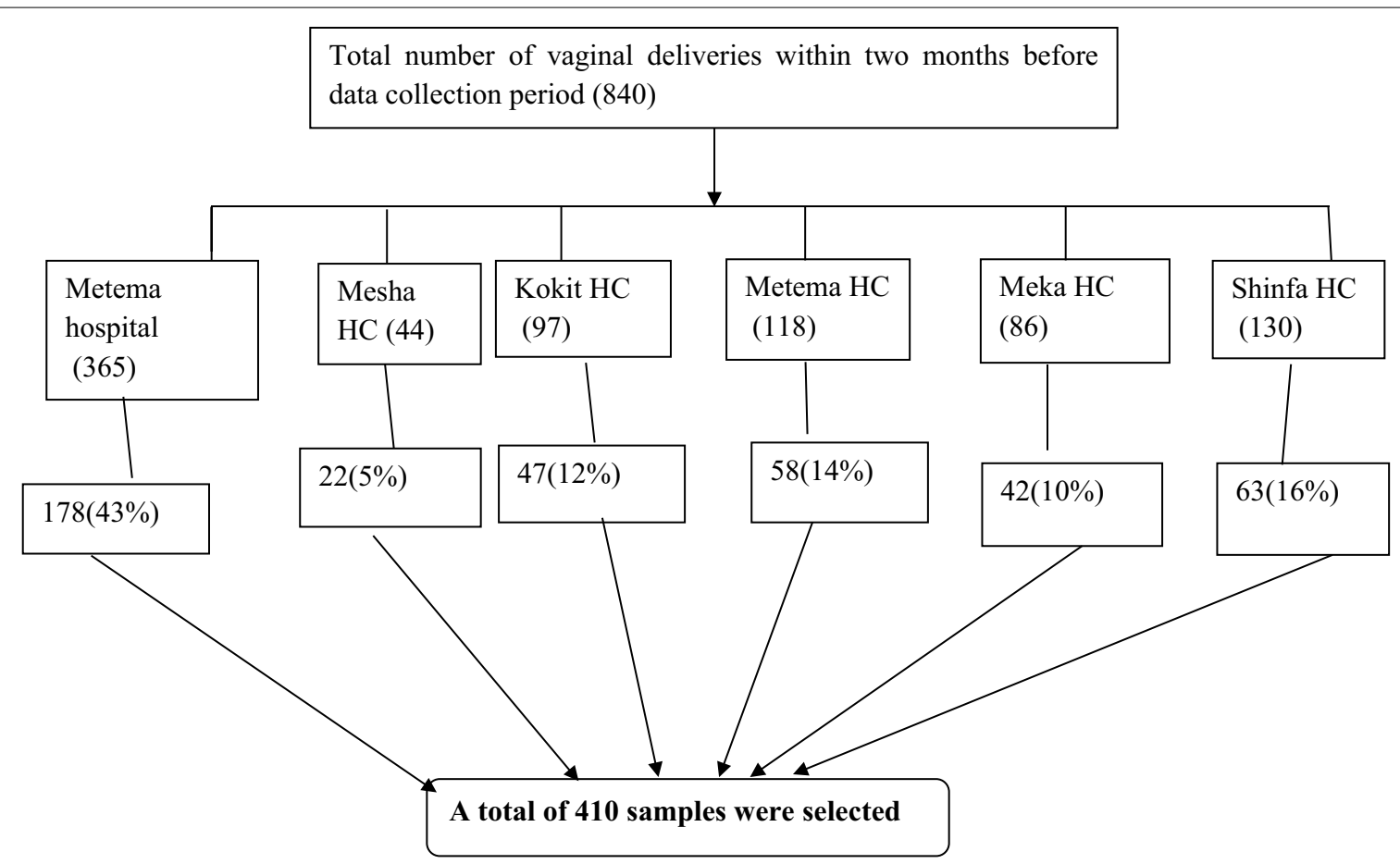

Fig. 1 Schematic presentation of sampling procedure for selection of study participants at public health facilitis in Metema district, 2020

version 3.1 and were exported in to stata/SE 14. The data were further recoded, cleaned for missing data outliers before analysis. Data were described using descriptive statistics like frequencies, tables, graph and median with interquartile range. Income level of rural and urban households was separately analyzed and merging them by using principal component analysis and finally wealth index with quintiles was generated. Bivariable analysis using binary logistic regression was done to all independent variables to see their association with the dependent variable. All variables with $\mathrm{p}$ value $<0.25$ in bivariable analysis were entered into the final multivariable logistic regression model. Then association between dependent and independent variables were assessed using AOR, 95\% $\mathrm{CI}$ and p-value. Variable with p-value $<0.05$ was considered statistically significant. Stepwise backward elimination was applied for variable selection and Hosmer and Lemshow's statistic test was checked for model fitness of a logistic regression which was Prob $>\mathrm{chi}^{2}$ of 0.5559 indicating fitted logistic model since it was greater than p-value of 0.05 . Additionally, the model was checked by using receiver operating characteristics which was 0.8851 (area under ROC curve $=0.8851$ ) which indicates excellent model on prediction of accuracy. Lastly Multi-collinearity with Variance inflation factor of each significant variable was checked and it was less than 10 so no multicollinearity between significant variables.

\section{Results}

This study indicated that the proportion of episiotomy at public health facilities in Metema District was 181(44.15\%) among 410 delivered mothers with (95\% CI $39.32 \%, 48.97 \%)$.

\section{Socio-demographic and economic characteristics of respondents}

There were a total of 410 mothers who gave birth through vaginal deliveries were interviewed with the response rate of $100 \%$. About, 240 (58.54\%) of respondents who gave birth were in the age group of 25-35 years. The median age of the respondents with interquartile range (IQR) were 27 [22-30] years and $234(57.07 \%)$ of respondents were rural residents. Regarding occupation from the total of respondents 259(63.2\%) were housewives. Related to the educational status of the respondents, about 201 (49\%) were attend primary school and 320 (78.05\%) were followers of orthodox religion.

The study finding showed that 98 (23.9\%) participants had lowest wealth index and $82(20 \%)$ participants had highest wealth index at household level (Table 1).

\section{Clinical and individual maternal factors}

From the total of respondents, 345 (84.15\%) were had ANC follow up during their pregnancy time and 302(73.7\%) of the respondents were multiparous. About, 
$390(95.1 \%)$ of respondents Onset of labor were spontaneous. Among mothers 25(33.78\%) had second degree tear during delivery at public health facilities in Metema district (Fig. 2) (Table 2).

\section{Clinical and individual child factor}

Gestational age of majority of the mothers 339(82.68\%) were term at the time of delivery. Regarding fetal condition, 293(71.46\%) laboring mothers were with normal condition of fetal heartbeat (Table 3).

\section{Technical factors}

Three hundred forty six (84.39\%) mothers were delivered vaginally, while 64(15.61\%) mothers were delivered by instrumental assisted vaginal delivery (Tables 4,5 ).

\section{Bivariable and multivariable logistic regression analysis of factors associated with episiotomy practice}

The bivariable analysis showed that, maternal age, vaginal instrumental delivery, oxytocin, birth spacing, ANC follow up history, educational status, fetal presentation, duration of second stage of labour, birth weight, onset of labour, and perineal laceration had an association with the episiotomy practice at $\mathrm{p}$-value of 0.25 and these variables were candidate for multivariable logistic regression. But, after multivariable logistic regression analysis, only maternal age, vaginal instrumental delivery, oxytocin, birth spacing and perineal tear were significantly associated with episiotomy at $\mathrm{p}$ value less than 0.05 at $95 \%$ confidence interval at public health facilities in Metema District, 2020. But other variables (party, time of delivery, Episiotomy previous history, known medical disease, residence, occupation, religion, wealth index, gestational age, fetal heart rate, presence of meconium, sex of the neonate, birth attendants and use of analgesia) had no association with episiotomy practice at $p$ value of 0.25 and were not candidate for multivariable logistic regression.

This study showed that mothers whose age group between 25 and 35 years were $89 \%$ less likely to be exposed for episiotomy than mothers whose age group were between 18 and 24 (AOR 0.11, 95\% CI 0.05, 0.25). Likewise, mothers whose age group between 36 and 49 were $70 \%$ less likely to be exposed for episiotomy than mothers whose age group were between 18 and 24 (AOR 0.3, 95\% CI 0.09, 0.99).

Regarding instrumental vaginal delivery, mothers whose labor were assisted by instrumental vaginal delivery were 3.04 times more likely to have episiotomy as compared to those delivered by normal vaginal delivery (AOR 3.04, 95\% CI 1.36, 6.78).

Laboring mothers who had used oxytocin were at 2.73 times more likely to be exposed for episiotomy than laboring mothers who did not use oxytocin drug (AOR $2.73,95 \%$ CI $1.19,6.25)$.

The odds of episiotomy practice were 4.76 times more likely among mothers who had birth spacing of 2 years and less than 2 years when compared with mothers who had birth spacing of more than 2 years (AOR 4.76, 95\% CI 2.31, 9.83).The odds of episiotomy practice were 3.56 times more likely among mothers who had perineal tear during delivery when compared with who had no perineal tear (AOR 3.56, 95\% CI 1.68, 7.55).

\section{Discussion}

This study revealed that the magnitude of episiotomy practice is $181(44.15 \%)$ with $(95 \%$ CI $39.32 \%, 48.97 \%)$ which was higher than the recommended value by the WHO [65]. This finding was lower than the previous finding at Saint Paul's Hospital Millennium Medical College in Addis Ababa which reported that the prevalence of episiotomy was $65.4 \%$ [43]. This could be due to the high risk population as the referral hospital deals with referral cases. Study done in Enugu, Southeast, Nigeria and Mulago National Referral Hospital, Uganda and also in Romania the magnitude of episiotomy was $62.1 \%, 73 \%$ and $71.4 \%$ respectively [34, 38, 66]. This variation might be explained by the difference in study area, study facilities. However, the magnitude of episiotomy practice found in this study was higher than previous studies conducted at Mizan Aman General Hospital and at public health institutions of Akaki Kality in Addis Ababa, which reported that the prevalence of episiotomy was found to be $30.6 \%$, and $35.2 \%$ respectively $[44,46]$. This might be due to the previous studies used smaller sample sizes (381, 338 and 310) were study participants respectively. The result of this study also higher than those studies found at King Abdulaziz university hospital in Saudi Arabia and in the United States the proportion of episiotomy were $(35 \%, 24.5 \%)$ respectively $[67,68]$. This difference might be due to health workers skill gap (gap for skill training) and country policies towards the selective use of episiotomy. The result of this study was comparable to a previous study done at public health institutions of Axum town, north Ethiopia, which reported that, the proportion of episiotomy practice was $41.44 \%$ [41]. The reason for those close results might be studying facilities; this study was conducted at one Hospital and health centers which was similar with a study done at Axum town.

The result of this study showed that instrumental vaginal delivery was associated with episiotomy practice. This study showed that mothers whose labor were assisted by instrumental vaginal delivery were 3.04 times more likely to have episiotomy as compared to those delivered by normal vaginal delivery (AOR 
Table 1 Socio-demographic and economic factors of mothers who delivered in Metema District, northwest, Ethiopia, 2020 ( $n=410$ )

\begin{tabular}{|c|c|c|c|c|c|}
\hline Variables & Frequency & Percentage (\%) & Variables & Frequency & Percentage (\%) \\
\hline Age group & & & Religion & & \\
\hline $18-24$ years & 138 & 33.7 & Orthodox & 320 & 78 \\
\hline $25-35$ years & 240 & 58.5 & Muslim & 86 & 21 \\
\hline $36-49$ years & 32 & 7.8 & Protestant & 4 & 1 \\
\hline Educational status & & & Residence & & \\
\hline No formal education & 132 & 32.2 & Urban & 176 & 43 \\
\hline Primary level & 201 & 49 & Rural & 234 & 57 \\
\hline Secondary level & 64 & 15.6 & & & \\
\hline Diploma and above & 13 & 3.2 & & & \\
\hline Occupation & & & Wealth index & & \\
\hline House wife & 259 & 63.2 & Lowest & 98 & 23.9 \\
\hline Farmer & 51 & 12.4 & Second & 66 & 16.1 \\
\hline Merchant & 72 & 17.6 & Middle & 83 & 20.2 \\
\hline Daily laborer & 8 & 2 & Fourth & 81 & 19.8 \\
\hline Government employee & 17 & 4.2 & Highest & 82 & 20 \\
\hline Student & 3 & 0.7 & & & \\
\hline
\end{tabular}

Table 2 Clinical and individual maternal factors who delivered in Metema district, northwest, Ethiopia, $2020(n=410)$

\begin{tabular}{|c|c|c|c|c|c|}
\hline Variables & Frequency & Percentage (\%) & Variables & Frequency & Percentage (\%) \\
\hline Parity & & & ANC follow-up history & & \\
\hline Primipara & 108 & 26.3 & Yes & 345 & 84.15 \\
\hline Multipara & 302 & 73.7 & No & 65 & 15.85 \\
\hline Birth spacing & & & Duration second stage of labour & & \\
\hline No delivery & 108 & 26.3 & $\leq 90 \min$ & 55 & 13.41 \\
\hline$\leq 2$ years & 95 & 23.2 & $>90 \min$ & 53 & 12.93 \\
\hline$>2$ years & 207 & 50.5 & & & \\
\hline Medical diseases & & & Duration of second stage of labour & & \\
\hline Yes & 30 & 7.32 & $\leq 90 \min$ & 55 & 13.41 \\
\hline No & 380 & 92.68 & $>90 \mathrm{~min}$ & 53 & 12.93 \\
\hline Time of delivery & & & Onset of labor & & \\
\hline Day & 122 & 29.8 & Spontaneous & 390 & 95.1 \\
\hline Night & 288 & 70.2 & Induced & 20 & 4.9 \\
\hline \multicolumn{6}{|c|}{ Perineal lacerations } \\
\hline Yes & 74 & 18.05 & & & \\
\hline No & 336 & 81.95 & & & \\
\hline
\end{tabular}

3.04, 95\% CI 1.36, 6.78), This finding is consistent with studies conducted in Mizan Aman, Axum, Addis Ababa and Nigeria [37, 41, 44, 69]. This might be due to cephalhaematoma, third and fourth degree perineal lacerations during instrumental vaginal delivery procedures.

This study also revealed that laboring mothers who had used oxytocin were at 2.73timesmore likely to be exposed for episiotomy than laboring mothers who did not use oxytocin drug (AOR 2.73, 95\% CI 1.19, 6.25). This finding is congruent with studies conducted in
Shire town and Northeast of Iran [42, 54]. This might be due to the fact that oxytocin can cause the uterus to contract too strong, which may affect the pattern of baby's heartbeat.

Moreover, mothers whose age group between 25 and 35 were $89 \%$ less likely to be exposed for episiotomy than mothers whose age group were between 18 and 24(AOR 0.11, 95\% CI 0.05, 0.25). This result is consistent with the study conducted in Gondar Referral Hospital, Shire Town, Nigeria and Iran [42, 54, 70, 71]. This might be suggests that loosen tenser (tight) 
Table 3 Clinical and individual child factors among mothers who delivered in Metema District, Northwest, Ethiopia, 2020 $(n=410)$

\begin{tabular}{|c|c|c|}
\hline Variables & Frequency & Percentage (\%) \\
\hline \multicolumn{3}{|l|}{ Sex of the neonate } \\
\hline Male & 242 & 59.02 \\
\hline Female & 168 & 40.98 \\
\hline \multicolumn{3}{|l|}{ Gestational age } \\
\hline Preterm & 16 & 3.9 \\
\hline Term & 339 & 82.68 \\
\hline Post term & 25 & 6.1 \\
\hline Unknown & 30 & 7.32 \\
\hline \multicolumn{3}{|l|}{ Birth weight } \\
\hline Low & 26 & 6.34 \\
\hline Normal & 333 & 81.22 \\
\hline Macrosomia & 51 & 12.44 \\
\hline \multicolumn{3}{|c|}{ Condition of fetal heart beat } \\
\hline Normal & 293 & 71.46 \\
\hline Bradycardia & 63 & 15.37 \\
\hline Tachycardia & 54 & 13.17 \\
\hline \multicolumn{3}{|l|}{ Fetal presentation } \\
\hline Vertex & 359 & 87.56 \\
\hline Breech & 49 & 11.95 \\
\hline Shoulder presentation & 2 & 0.49 \\
\hline \multicolumn{3}{|l|}{ Presence of meconium } \\
\hline Yes & 65 & 15.85 \\
\hline No & 345 & 84.15 \\
\hline
\end{tabular}

Table 4 Technical factors for episiotomy in Metema district, Northwest, Ethiopia, $2020(n=410)$

\begin{tabular}{lll}
\hline Variables & Frequency & Percentage (\%) \\
\hline Use of oxytocin & & \\
Yes & 59 & 14.39 \\
No & 351 & 85.61 \\
Fundal pressure & & \\
Yes & 93 & 22.68 \\
No & 317 & 77.32 \\
Use of analgesia & & \\
Yes & 15 & 3.66 \\
No & 395 & 96.34 \\
Instrumental vaginal delivery & & \\
Yes & 64 & 15.61 \\
No & 346 & 84.39 \\
Birth attendants & & \\
Midwife & 386 & 94.15 \\
HO & 5 & 1.22 \\
Nurse & 4 & 0.98 \\
IESO & 9 & 2.20 \\
Doctor & 6 & 1.46 \\
\hline
\end{tabular}

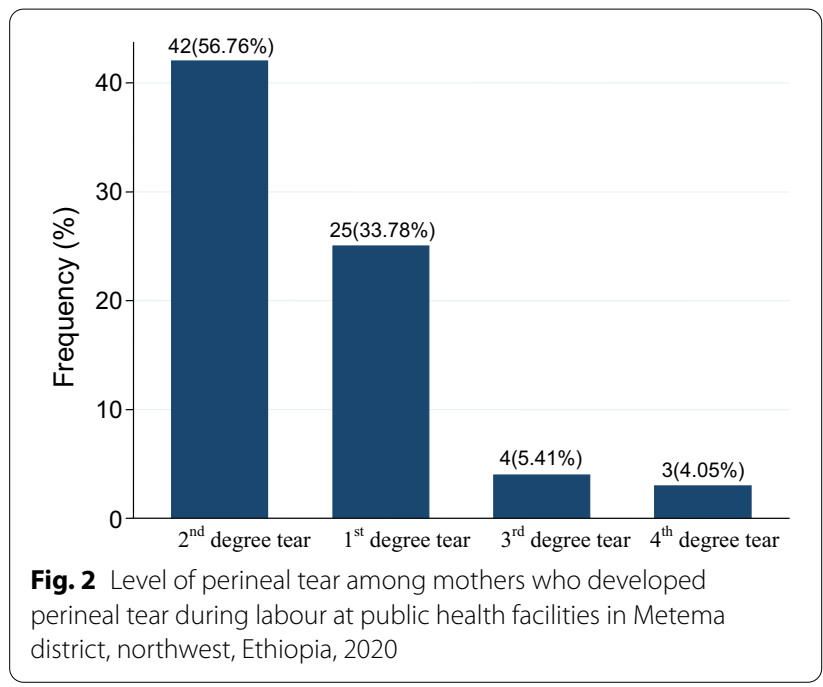

musculature of multiparous for increased releasing period of cephalic pole presentation which in turn might not lead to health professionals to do episiotomy.

Likewise birth spacing was significantly associated with episiotomy practice. The odds of episiotomy practice were 4.76 times more likely among mothers who had birth spacing of 2 years and less than 2 years when compared with mothers who had birth spacing of more than 2 years (AOR 4.76, 95\% CI 2.31, 9.83). This might be due to the fact that those mothers who had short birth spacing their reproductive organs become weak and delicate this might be a risk for perineal tear.

In this study, the odds of episiotomy practice were 3.56 times more likely among mothers who had perineal tear during delivery when compared with who had no perineal tear (AOR 3.56, 95\% CI 1.68, 7.55). This study is consistent with the study conducted in Mizan Aman, Kurdistan region and Israel [44, 49, 52]. This might be due to a reason that episiotomy in such cases is supposed to lower the increased risk of obstetric anal sphincter injuries in subsequent deliveries.

This study had some limitations. It was difficult to know clearly the magnitude of mothers who got episiotomy care due to an indication for episiotomy or due to false initiation of episiotomy.

\section{Conclusion}

The proportion of episiotomy in this study was higher than the recommended value by the WHO (5-10\%). Maternal age, vaginal instrumental delivery, oxytocin drug, birth spacing and perineal tear were independent factors for episiotomy practice at public health facilities in Metema District. Therefore reduce unnecessary interventions like giving oxytocin and using 
Table 5 Bivariable and multivariable logistic regression analysis of factors associated with practice of episiotomy at public health facilities in Metema district, Northwest, Ethiopia, 2020

\begin{tabular}{|c|c|c|c|c|}
\hline \multirow[t]{2}{*}{ Variables } & \multicolumn{2}{|c|}{ Episiotomy practice } & \multirow[t]{2}{*}{$\operatorname{COR}(95 \% \mathrm{Cl})$} & \multirow[t]{2}{*}{ AOR $(95 \% \mathrm{Cl})$} \\
\hline & Yes (\%) & No (\%) & & \\
\hline \multicolumn{5}{|l|}{ Age group } \\
\hline $18-24$ years & $110(26.83)$ & $28(6.83)$ & 1 & 1 \\
\hline $25-35$ years & $50(12.20)$ & $190(46.34)$ & $0.07(0.04, .11)$ & $0.11(0.05,0.25)$ \\
\hline $36-49$ years & $21(5.12)$ & $11(2.68)$ & $0.49(.21,1.12)$ & $0.3(0.09,0.99)$ \\
\hline \multicolumn{5}{|l|}{ ANC follow up history } \\
\hline Yes & $130(31.71)$ & $215(52.44)$ & $0.17(.09, .31)$ & $1.80(0.78,4.15$ \\
\hline No & $51(12.44)$ & $14(3.41)$ & 1 & 1 \\
\hline \multicolumn{5}{|l|}{ Vaginal instrumental delivery } \\
\hline Yes & $47(11.46)$ & $17(4.15)$ & $4.37(2.41,7.93)$ & $3.04(1.36,6.78)$ \\
\hline No & $134(32.68)$ & $212(51.71)$ & 1 & 1 \\
\hline \multicolumn{5}{|l|}{ Educational status } \\
\hline No formal education & 89 & 43 & $4.66(1.36,15.98)$ & $0.85(0.22,3.36)$ \\
\hline Primary level & 69 & 132 & $1.18(0.35,3.96)$ & $0.28(0.07,1.10)$ \\
\hline Secondary level & 19 & 45 & $0.95(0.26,3.47)$ & $0.39(0.09,1.67)$ \\
\hline Diploma and above & 4 & 9 & 1 & 1 \\
\hline \multicolumn{5}{|l|}{ Oxytocin } \\
\hline Yes & $43(10.49)$ & $16(3.90)$ & $4.15(2.25,7.65)$ & $2.73(1.19,6.25)$ \\
\hline No & $138(33.66)$ & $213(51.95)$ & 1 & 1 \\
\hline \multicolumn{5}{|l|}{ Birth spacing } \\
\hline No previous delivery history & $35(8.54)$ & $73(17.80)$ & $9.91(5.77,16.99)$ & $1.44(0.59,3.53)$ \\
\hline Two and less than 2 years & $72(17.56)$ & $23(5.61)$ & $14.87(8.23,26.86)$ & $4.76(2.31,9.83)$ \\
\hline More than 2 years & $171(41.71)$ & $36(8.78)$ & 1 & 1 \\
\hline \multicolumn{5}{|l|}{ Perineal tear } \\
\hline Yes & $59(14.39)$ & $15(3.66)$ & $6.89(3.75,12.68)$ & $3.56(1.68,7.55)$ \\
\hline No & $122(29.76)$ & $214(52.20)$ & 1 & 1 \\
\hline
\end{tabular}

instrumental vaginal delivery during normal labor and it is best to know common understanding on perineal tear by preparing morning session on job training.

Abbreviations

AIDS: Acquired immune deficiency syndrome; ANC: Antenatal care; AOR: Adjusted odds ratio; APH: Ante-partum hemorrhage; $\mathrm{Cl}$ : Confidence interval; COR: Crude odds ratio; DM: Diabetes mellitus; HC: Health center; HIV: Human immune deficiency virus; HTN: Hypertension; IESO: Integrated Emergency Surgine Officer; LMIC: Low and Middle Income Countries; PIH: Pregnancy induced hypertension; STATA: Software for Statistics and Data Science; WHO: World Health Organization.

\section{Acknowledgements}

We would like to express deepest gratitude to our study participants, data collectors and supervisors for giving their valuable time and information for the success of this research work.

\section{Authors' contributions}

MA: Conception of research protocol, study design, literature review, data extraction, data analysis, interpretation and drafting the manuscript. MAA, LY, GG, DBK, and WG contribute on data extraction, quality assessment, data analysis and manuscript review and TDC edition \& validation. All authors have read and approved the manuscript.

\section{Funding}

Not applicable.

Availability of data and materials

All data are available in the manuscript.

\section{Declarations}

\section{Ethics approval and consent to participate}

Ethical clearance was obtained from Debre Markos University health science college ethical committee. A formal letter was submitted to all the concerned bodies in the study institution to obtain co-operation in facilitating the study. The objective, benefit and risks of the study to the study participants were explained by data collectors to get informed written consent prior to data collection. Respondents had the right to refuse or decline from the study at any time without any form of prejudice. The information they gave us would not to be used for any purpose other than the study and the information they gave us not contain their name or any identifiers which refers to them.

\section{Consent for publication}

Not applicable.

\section{Competing interests}

The authors declare that they have no competing interests. 


\section{Author details}

${ }^{1}$ Metema Health District, Metema, Ethiopia. ${ }^{2}$ Department of Public Health, Debre Markos University, Debre Markos, Ethiopia.

Received: 16 December 2020 Accepted: 25 June 2021 Published online: 02 July 2021

\section{References}

1. Berkowitz LR, Foust-Wright C, Lickwood C, Eckler K. Approach to episiotomy. UpToDate Last updated. 2016;26

2. Carroli G, Belizan J. Episiotomy for vaginal birth. Cochrane database of systematic reviews. 1999(3).

3. Kalis V, Rusavy Z, Prka M. Episiotomy. Childbirth trauma. New York: Springer; 2017. p. 69-99.

4. Fodstad K, Laine K, Staff AC. Different episiotomy techniques, postpartum perineal pain, and blood loss: an observational study. Int Urogynecol J. 2013;24(5):865-72.

5. Sooklim R, Thinkhamrop J, Lumbiganon P, Prasertcharoensuk W, Pattamadilok J, Seekorn K, et al. The outcomes of midline versus medio-lateral episiotomy. Reprod Health. 2007;4:10.

6. World Health Organization. WHO recommendations: intrapartum care for a positive childbirth experience. Geneva: World Health Organization; 2018.

7. Clesse C, Lighezzolo-Alnot J, De Lavergne S, Hamlin S, Scheffler M. Statistical trends of episiotomy around the world: comparative systematic review of changing practices. Health Care Women Int. 2018;39(6):644-62.

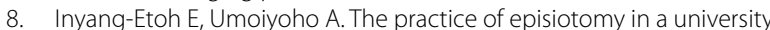
teaching hospital in Nigeria: how satisfactory? Int J Med Biomed Res. 2012:1(1):68-72

9. Aasheim V, Nilsen ABV, Reinar LM, Lukasse M. Perineal techniques during the second stage of labour for reducing perineal trauma. Cochrane Database Syst Rev 2017(6)

10. Jiang H, Qian X, Carroli G, Garner P. Selective versus routine use of episiotomy for vaginal birth. Cochrane Database of Systematic Reviews. 2017(2)

11. World Health Organization. WHO recommendations for prevention and treatment of maternal peripartum infections. Geneva: World Health Organization; 2016

12. Lede RL, Belizán JM, Carroli G. Is routine use of episiotomy justified? Am J Obstet Gynecol. 1996;174(5):1399-402.

13. Johanson R. Obsteric procedures. In: Edmonds DK, editor. Dewhurst's textbook of obsterics and gynaecology for postgraduates. New Jersey: Blackwell Science; 1999.

14. Hussein SAAA, Dahlen $\mathrm{H}$, Schmied V. What makes episiotomy rates change? A systematic review of the literature. Int J Childbirth. 2012;2(1):29-39.

15. Aguiar M, Farley A, Hope L, Amin A, Shah P, Manaseki-Holland S. Birthrelated perineal trauma in low-and middle-income countries: a systematic review and meta-analysis. Maternal Child Health J. 2019:1-23.

16. Thacker S, Banta H. Benefits and risks of episiotomy: an interpretive review of the English language literature, 1860-1980. Obstet Gynecol Survey 1983. 2003;38(6):322-38

17. Harrison RF, Brennan M, North P, Reed J, Wickham E. Is routine episiotomy necessary? Br Med J (Clin Res Ed). 1984;288(6435):1971-5.

18. Howard D, DeLancey JO, Burney RE. Fistula-in-ano after episiotomy. Obstet Gynecol. 1999;93(5):800-2

19. Barranger $E$, Haddad B, Paniel BJ. Fistula in ano as a rare complication of mediolateral episiotomy: report of three cases. Am J Obstet Gynecol. 2000;182(3):733-4.

20. Signorello LB, Harlow BL, Chekos AK, Repke JT. Midline episiotomy and anal incontinence: retrospective cohort study. BMJ. 2000:320(7227):86-90

21. Larsson P-G, Platz-Christensen J-J, Bergman B, Wallstersson G. Advantage or disadvantage of episiotomy compared with spontaneous perineal laceration. Gynecol Obstet Invest. 1991;31(4):213-6.

22. Sule S, Shittu S. Puerperal complications of episiotomies at Ahmadu Bello University Teaching Hospital, Zaria. Nigeria East Afr Med J. 2003:80(7):351-6.
23. Karaçam Z, Ekmen H, Çalişır $H$, Şeker S. Prevalence of episiotomy in primiparas, related conditions, and effects of episiotomy on suture materials used, perineal pain, wound healing 3 weeks postpartum, in Turkey: A prospective follow-up study. Iran J Nurs Midwifery Res. 2013;18(3):237.

24. Sleep J, Grant A. West Berkshire perineal management trial: three year follow up. Br Med J (Clin Res Ed). 1987;295(6601):749-51.

25. Ejegård H, Ryding EL, Sjögren B. Sexuality after delivery with episiotomy: a long-term follow-up. Gynecol Obstet Invest. 2008;66(1):1-7.

26. Adama O, Natacha LB, Smaila O, Alexis SY, Francoise MT, Charlemagne OM, et al. Episiotomy: epidemiological aspects, indications and prognosis in the Bogodogo Health District. Open J Obst Gynecol. 2018:8(13):1354

27. Karaçam Z, Eroğlu K. Effects of episiotomy on bonding and mothers' health. J Adv Nurs. 2003:43(4):384-94.

28. Demeulemeester V, Van Hautem H, Cools F, Lefevere J. Transplacental lidocaine intoxication. J Neonatal-perinatal Med. 2018;11(4):439-41.

29. Liljestrand J. Episiotomy for vaginal birth: RHL commentary (last revised: 20 October 2003). Geneva: World Health Organization Reproductive Health Library; 2003

30. World Health Organization. Prevention of HIV in infants and young children: review of evidence and WHO's activities. Geneva: World Health Organization; 2002

31. Study EC. Risk factors for mother-to-child transmission of HIV-1. Lancet. 1992;339(8800):1007-12.

32. Graham ID, Carroli G, Davies C, Medves JM. Episiotomy rates around the world: an update. Birth. 2005;32(3):219-23.

33. Goueslard K, Cottenet J, Roussot A, Clesse C, Sagot P, Quantin C. How did episiotomy rates change from 2007 to 2014? Population-based study in France. BMC Pregnancy Childbirth. 2018;18(1):208.

34. Pasc A, Navolan D, Pușcașiu L, Ionescu CA, Szasz FA, Carabineanu A, et al. A multicenter cross-sectional study of episiotomy practice in Romania. J Eval Clin Pract. 2019;25(2):306-11.

35. Webb DA, Culhane J. Hospital variation in episiotomy use and the risk of perineal trauma during childbirth. Birth. 2002;29(2):132-6.

36. Lorenz N, Nougtara A, Garner P. Episiotomy in Burkina Faso. Trop Doct. 1998;28(2):83-5.

37. Alayande BT, Amole IO, Akin D. Relative frequency and predictors of episiotomy in Ogbomoso, Nigeria. Internet Journal of Medical UpdateEJOURNAL. 2012;7(2)

38. Izuka E, Dim C, Chigbu C, Obiora-Izuka C. Prevalence and predictors of episiotomy among women at first birth in Enugu, south east Nigeria. Ann Med Health Sci Res. 2014:4(6):928-32.

39. Bergh JEVD, Sueters M, Segaar M, Roosmalen JV. Determinants of episiotomy in rural Zimbabwe. Acta Obstet Gynecol Scand. 2003;82(10):966-8

40. Worku S, Mitku Y, Getahun S. Episiotomy practice and its associated factor among women who gave birth at Public Health Institutions of Akaki Kality in Addis Ababa, Ethiopia. Clin Mother Child Health. 2019;16:318.

41. Yemaneh Y, Sahile E, Alehegn A, Girma A, Robles C. Assessment of the proportion and associated factors of episiotomy at Public Health Institutions of Axum Town, Tigray Region, North Ethiopia, 2015. Crit Care Obst Gyne. 2017;3:11.

42. Niguse K, Gidey G, Gebrehiwot H, Abay M, Getachew D, Worku T. Episiotomy practice and its associated factors among mothers who gave birth vaginally at public health institutions of Shire Town Northern Ethiopia. Infection. 2016:8:9.

43. Tefera T, Kebede B, Mekonen T. Prevalence of episiotomy and factors associated with practice of episiotomy at Saint Paul's Hospital millennium medical college: a cross sectional study. Ethiop J Reprod Health. 2019;11(3):8.

44. Kumera MG, Ademe BW, Akessa GM. Assessment of Episiotomy Practice in Mizan Aman General Hospital, Ethiopia. Assessment. 2015;20.

45. de Carvalho CCM, Souza A, Moraes O. Prevalence and factors associated with practice of episiotomy at a maternity school in Recife, Pernambuco, Brazil. Revista Da Associacao Medica Brasileira. 2010.

46. Worku S, Mitku Y, Getahun S. Episiotomy practice and its associated factor among women who gave birth at Public Health Institutions of Akaki Kality in Addis Ababa, Ethiopia. Clin Mother Child Health. 2019;16(318):2.

47. Innocent N, Philémon MM, Prince I, Justine Y, Ntakwinja M, Olivier N, et al. Factors associated with episiotomy practice in Bukavu, Democratic 
Republic of the Congo. Int J Reprod Contracep Obst Gynecol. 2018;7(7):2554.

48. Braga GC, Clementino STP, Luz PFNd, Scavuzzi A, Noronha Neto C, Amorim MMR. Risk factors for episiotomy: a case-control study. Revista da Associação Médica Brasileira. 2014;60(5):465-72.

49. Sagi-Dain L, Sagi S. Indications for episiotomy performance-a crosssectional survey and review of the literature. J Obstet Gynaecol. 2016;36(3):361-5.

50. Owa OO, Eniowo AR, llesanmi OS. Factors associated with episiotomy among parturients delivering in a tertiary care centre in Nigeria. Int $J$ Res Med Sci. 2015;3:836-40

51. Hirayama F, Koyanagi A, Mori R, Zhang J, Souza J, Gülmezoglu A. Prevalence and risk factors for third-and fourth-degree perineal lacerations during vaginal delivery: a multi-country study. BJOG. 2012;119(3):340-7.

52. Ahmed HM. Midwives' clinical reasons for performing episiotomies in the Kurdistan Region: are they evidence-based? Sultan Qaboos Univ Med J. 2014;14(3):e369.

53. Marai W. A two years retrospective review of episiotomy at Jimma Teaching Hospital, southwestern Ethiopia. Ethiop Med J. 2002;40(2):141-8.

54. Rasouli M, Keramat A, Khosravi A, Mohabatpour Z. Prevalence and factors associated with episiotomy in Shahroud City, northeast of Iran. Int J Womens Health Reprod Sci. 2016;4(3):125-9.

55. Hernández Pérez J, Azón López E, Mir Ramos E, Peinado Berzosa R, Val Lechuz B, Mérida DA. Factors affecting the performance of a selective episiotomy in nulliparous women. Julio. 2014;35:412-24.

56. Carvalho C, Souza A, Moraes OF. Prevalence and factors associated with practice of episiotomy at a maternity school in Recife, Pernambuco, Brazil. Revista da Associacao Medica Brasileira (1992). 2010;56(3):333-9.

57. Hartmann K, Viswanathan M, Palmieri R, Gartlehner G, Thorp J, Lohr KN. Outcomes of routine episiotomy: a systematic review. JAMA. 2005;293(17):2141-8.

58. Higuera V. Episiotomy: Procedure, Complications, and Recovery. healthline parenthood. 2016.

59. Gelaw YA, Magalhães RJS, Assefa Y, Williams G. Spatial clustering and socio-demographic determinants of HIV infection in Ethiopia, 2015-2017. Int J Infect Dis. 2019;82:33-9.
60. Office MDH. Anual plan achivements in 2019. 2019.

61. West Gondar Zone 2012 Ethiopian fisical year annual plan. 2019 July 15/2019. Report No.

62. Post M. HTSP 101: everything you want to know about healthy timing and spacing of pregnancy. Washington, DC: Extending Service Delivery Project; 2008.

63. Dahlen HG, Ryan M, Homer CS, Cooke M. An Australian prospective cohort study of risk factors for severe perineal trauma during childbirth. Midwifery. 2007:23(2):196-203.

64. Central Statistical Aency Addis Ababa E. Ethiopian Demographic and health survey. 2016.

65. World Health Organization. WHO recommendation on episiotomy policy. THE WHO HEALTH LIBRARY. 2018.

66. Pebolo PF, Judith A, Dan KK. Prevalence and factors associated with episiotomy practice among primiparous women in mulago national referral hospital Uganda. International Journal of Pregnancy \& Child Birth. 2019;5(5).

67. Oraif A. Routine episiotomy practice at a tertiary care center in Saudi Arabia. Open J Obst Gynecol. 2016;6(13):794-7.

68. Frankman EA, Wang L, Bunker CH, Lowder JL. Episiotomy in the United States: has anything changed? Am J Obst Gynecol. 2009;200(5):573.

69. Kiros K, Lakew Z. Magnitude of episiotomy in a teaching hospital in Addis Ababa, Ethiopia. Ethiop Med J. 2006;44(3):205-9.

70. Chigbu B, Onwere S, Aluka C, Kamanu C, Adibe E. Factors influencing the use of episiotomy during vaginal delivery in South Eastern Nigeria. East Afr Med J. 2008;85(5):240-3.

71. Teshome Y, Mekonen M, Sisay T, Chala G, Mengistu A, Shewasinad S, et al. Prevalence of episiotomy and its associated factors in university of gondar comprehensive specialized referral hospital: a retrospective study from Ethiopia. Am J Life Sci. 2020;8(1):9-13.

\section{Publisher's Note}

Springer Nature remains neutral with regard to jurisdictional claims in published maps and institutional affiliations.
Ready to submit your research? Choose BMC and benefit from:

- fast, convenient online submission

- thorough peer review by experienced researchers in your field

- rapid publication on acceptance

- support for research data, including large and complex data types

- gold Open Access which fosters wider collaboration and increased citations

- maximum visibility for your research: over $100 \mathrm{M}$ website views per year

At BMC, research is always in progress.

Learn more biomedcentral.com/submissions 